\title{
Childhood Diabetes and Mood Disorders
}

\author{
Rachel Lundberg ${ }^{1}$, Puneet Narang ${ }^{2}$ and Steven Lippmann ${ }^{3^{*}}$ \\ ${ }^{1}$ Medical Student, University of Minnesota, Minneapolis, MN, USA \\ ${ }^{2}$ Staff Physician and Lead ECT Psychiatrist, Regions Hospital, Minneapolis-St. Paul, MN, USA \\ ${ }^{3}$ Professor of Psychiatry, University of Louisville School of Medicine, Louisville, KY, USA
}

*Correspondence author: Steven Lippmann, 550 S Jackson Street, ACB first floor, Louisville, KY, USA 40202; Tel: 502-895-8330; E-mail: sblipp01@louisville.edu

Received Date: September 26, 2014, Accepted Date: November 10, 2014, Published Date: November 17, 2014

Copyright: (c) 2015, Lundberg et al., This is an open-access article distributed under the terms of the Creative Commons Attribution License, which permits unrestricted use, distribution, and reproduction in any medium, provided the original author and source are credited.

\begin{abstract}
Clinical vignette

A 16 year old male wasdiagnosed with type 1 diabetes mellitus three months ago. His condition was uncontrolled with a hemoglobin A1c (HbA1c) of 9.0\%. He has been meetingmonthly with his diabetes treatment team, but struggling at carbohydrate counting and managing insulin. The patient'smother has a history of depression,polysubstance abuse, and frequently failed to attendscheduled appointments. At the three month follow up visit, his $\mathrm{HbAlc}$ was $9.6 \%$. He now reported sadness, low energy, and insomnia, decreased interest in sports or social contact, and feeling hopeless.
\end{abstract}

Keywords: Diabetes; Diabetes mellitus; Mood disorders; Depression; Affective illness; Children; Pediatrics

\section{Introduction}

Type 1 diabetes mellitus (T1DM) is a disorder of impaired insulin secretion and glucose regulation. The initial diagnosis is most commonly made in children and adolescents who often present with an acute illness followed by several weeks of polyuria, polyphagia, polydipsia, and weight loss. Sometimes the diagnosis is determined by an incidentally noted plasma glucose elevation. The diagnosis and management of T1DM is a significant stressor for children and parents [1]. T1DM creates new daily demands and significant lifestyle changes for families [2]. In children and adolescents with T1DM, depression is the single most frequent co-morbid disorder.

\section{Prevalence}

In one longitudinal investigation of 92 children (ages 8-13 at time of T1DM diagnosis) followed for 10 years, the estimated prevalence of a psychiatric disorder was $47.6 \%$. Major depression was the most frequent diagnosis at $27.5 \%$, followed by conduct and anxiety disorders. The highest incidence of depression was in the first year after diagnosis. Within three months, $33.4 \%$ of children were documented to have an adjustment disorder [2]. Depression prevalence was at $20 \%$ in another study of children and adolescents with T1DM [3]. Significantly higher than the $11.2 \%$ lifetime prevalence of depression in the general adolescent population [4].

Among 92 children with T1DM who were studied for 10 years, 24 of them who developed depression were compared to 30 depressed control subjects for the frequency of depression recurrence. There were 33 depressive episodes among the 24 youths: 16 experiencedone episode, seven reported tworelapses, and three episodes were documented in one case.During depression, there was $42 \%$ comorbidity with another psychiatric disorder, most commonly anxiety. The mean time elapsed from the initial diagnosis of T1DM and the first affective illness diagnosis was 4.2 years; however, over one-third ofsubjects had their initial complaints within a year of diagnosis. Euthymia recovery and the risk for a subsequent relapse did not appear to be affected by having T1DM [5].

\section{Risk Factors}

Although T1DM does not seem to be a risk factor for affective illness recurrence, there is research examining issues that contribute toits prevalence in youths with T1DM. There is mixed data about gender being a predispositionfor depression in T1DM; one study documented higher rates in females [6] another reportedno difference in gender prevalence [5]. Maternal depression was arisk factor for depression in youths with T1DM; this may be caused by a variety of biopsychosocial factors including genetics, family dynamics, and parental support or involvement in diabetes care [5].

Although the prevalence of type 1 diabetes is similar among children from different ethnic and racial backgrounds, there is a higher prevalence of type 2 diabetes in Hispanic and black youth. Black and Hispanic children with T1DMalso have poorer glycemic control than white children; however; it is unclear whether race is an independent risk factor for the onset of depression in minority children with diabetes [7]. Young adults with socioeconomic indicatorssuch as hospitalizations, sick leave, or receiving disability pensions contributed more to depression than did diabetes; however; this endocrinopathy can lead to higher prevalences of these risk factors and they indirectly contribute to depressive illness [8].

Diabetes mellitus is a significant stressor and requires major lifestyle adjustments including glucose monitoring, carbohydrate counting, and insulin injections. Children cope with the diagnosis and lifestyle changes associated with diabetes in different ways. Younger children may not understand the impact when first diagnosed, but do gain more understandingover time. Any inadequate coping skills contribute to the development of depression [5]. 
Parental and family conflict plays a role in depressive symptoms. Family conflict may be diabetes-specific, relating to responsibilities around glucose management and insulin therapy. As adolescents gain independence and take personal responsibility for theirown care, this can create tension andinduce depression. Depressed parents will often provide less physical andemotional support to their children,having less energy and motivation to help in the routine of diabetes management [9].

\section{Clinical Impact}

There is a correlation between depression and poor diabetic control in children. Those with depression and T1DM evidence less blood glucose checking and higher HbAlc values (9). Parental involvement in those experiencing modest or severe depression has no affect on HbAlc [10]. Yet, depression may affect adherence to diabetes treatment due to decreased interest, energy, and motivationwhich subsequently yields poor diabetic control,and may worsen symptoms of guilt or hopelessness [11]. There is a $27 \%$ increase in theprobability of depression per unit rise in HbAlc reports [12]. Prospective researchmight identifythe relationship between depressed mood and high $\mathrm{HbAlc}$ values.

Depression in young people with T1DM has a variety of consequences. In addition to contributing to poor glucose control which can negatively impact long term health outcomes, depression reduces quality of life and increases suicide rates. There are moresuicidesin children co-morbid withdepression and T1DM than in those with either condition alone. In 95 children 12 years after the onset of T1DM, there was a $58 \%$ history of suicidal ideation.About $6 \%$ ofthem had attempted suicide for a total of 11 attempts; six of the attempts used diabetes medications as the suicide method. No children died as a result of these attempts. Suicidal thoughts in the first year of T1DM diagnosis were related to poor compliance with diabetes care [13]. Adolescents are already a high risk group for suicide due to the challenges of puberty, peer pressures, and independence from parental control [14].

\section{Prevention and Management of Depression in Diabetic Children}

Given the negative consequences that depression can have on diabetes management and quality of life, it is important to assess and provide psychosocial interventions as needed. Diabetes clinics should institute an integrated team approach with physicians, diabetes educators, health psychologists, social workers, and nutritionists to approach management from a bio-psychosocialmode of intervention [15]. Many children may not be interested in discussing their emotional concerns, but it is valuable to have behavioral specialists available [6]. They shouldbe involved in the initial evaluationof a newly diagnosed child with T1DM and be available at follow up visits.Children who receive coping skills training including social problem solving, cognitive behavior modification, and conflict resolution have better diabetes control and better quality of life [16]. Screening for depression is recommended annually in all children with T1DM who areover nine years of age [1].

Childhood depression with diabetes mellituscan persist into adulthood. The prevalence of major depressive disorder is approximately 3-4 times higher in adults with type 1 diabetes mellitus than with controls. Depression and T1DM in adulthood also contributes to poor glycemic control and negative long term consequences [17]. Less is known about the relationship between other mood disorders and T1DM, but clinicians should evaluate for depression, particularly if there are symptoms or a positive family history.

In conclusion, there is a higher prevalence of depression in children with type 1 diabetes mellitus than the general pediatric population. The diagnosis of T1DM is a significant stressor for children and families and requires lifestyle changes. Depression is important to recognize and treat because it can contribute to poor blood glucose control and adverse psychosocial outcomes. Clinicians should consider risk factors and screen all T1DM patients over nine years of age.Behavioral specialists should intervene with all families having a diabetic child to help overcome psychosocial barriers and minimize depressive features.

\section{Case conclusion}

Our patient had several risk factors for the development of depression including an acute stressor, lack of parental support, and a history of maternal depression. As described above, approximately $1 / 3$ of children diagnosed with T1DM develop an adjustment disorder within 3 months of diagnosis. This patient's development of depression is not unexpected and may have been prevented by an initial meeting with a health psychologist to learn effective coping skills. This case stresses the importance of early screening for depression as his $\mathrm{HbAlC}$ worsened as he developed depressive symptoms.

At the three month follow up visit, he was referred to a health psychologist, and his physicianprescribed fluoxetine $20 \mathrm{mg}$ daily. Over the next six months, he met regularly with the psychologist, learning coping skills on how to manage diabetes. He became more comfortable in treating the illnessdespite his family remaining uninvolved. Ata one year follow up, the HbAlc dropped to $7.6 \%$, and depressive symptoms significantly improved.He has since weaned off fluoxetine, but close follow up is indicated since he remains at an increased risk for subsequent depressive episodes.

\section{References}

1. Silverstein J, Klingensmith G, Copeland K (2005) Care of children and adolescents with type 1 diabetes: a statement of the American Diabetes Association. Diabetes Care 28: 186-212.

2. Kovacs M, Obrosky DS, Goldston D (1997) Psychiatric Disorders in Youths with IDDM: Rates and Risk Factors. Diabetes Care 20: 36-43.

3. Cho E, Shin SH, Eun S (2013) Psychological characteristics of Korean children and adolescents with type 1 diabetes mellitus. Ann Pediatr Endocrinol Metab 18: 122-127.

4. Merikangas KR, He J, Burstein M (2010) Lifetime prevalence of mental disorders in U.S. adolescents: Results from the National Comorbidity Study- Adolescent Supplement (NCS-A). J Am Acad Child Adolesc Psychiatry 49: 980-989.

5. Kovacs M, Obrosky DS, Goldston D (1997) Major Depressive Disorder in Youths with IDDM. Diabetes Care 20: 45-50.

6. De Wit M, Snoek FJ (2011) Depressive symptoms and unmet psychological needs of Dutch youth with type 1 diabetes: results of a websurvey. Pediatr Diabetes 12: 172-176.

7. Berry JG, Bloom S, Foley S (2010) Health Inequity in Children and Youth With Chronic Health Conditions. Pediatrics 126: S111-119.

8. Lind T, Waernbaum I, Berhan Y (2012) Socioeconomic factors, rather than diabetes mellitus per se, contribute to an excessive use of antidepressants among young adults with childhood onset type 1 diabetes mellitus: a register-based study. Diabetologia 55: 617-624. 
Citation: Lundberg R, Narang P, Lippmann S (2015) Childhood Diabetes and Mood Disorders. J Psychiatry 18: 206. doi:

9. Hood KK, Huestis S, Maher A (2006) Depressive Symptoms in Children and Adolescents with Type 1 Diabetes: Association with diabetes-specific characteristics. Diabetes Care 29: 1389-1391.

10. Wu YP, Hilliard ME, Rausch J (2013) Family involvement with the diabetes regimen in young people: the role of adolescent depressive symptoms. Diabetes Med 30: 596-602.

11. McGrady ME, Laffel L, Drotar D (2009) Depressive symptoms and glycemic control in adolescents with type 1 diabetes. Diabetes Care 32: 804-806.

12. Hassan K, Loar R, Anderson B (2006) the role of socioeconomic status, depression, quality of life, and glycemic control in type 1 diabetes. J Pediatrics 149: 526-531.

13. Goldston D, Kovacs M, Ho V (1994) Suicidal ideation and suicide attempts among youth with insulin-dependent diabetes mellitus. J Am Acad Child Adolesc Psychiatry 33: 240-246.
14. Goldston DB, Kelley AE, Reboussin DM (1997) Suicidal Ideation and behavior and noncompliance with the medical regimen among diabetic adolescents. J Am Acad Child Adolesc Psychiatry 26: 1528-1536.

15. Dantzer C, Swendsen J, Maurice-Tison S (2003) Anxiety and depression in juvenile diabetes: a critical review. ClinPsychol Review 23: 787-800.

16. Grey M, Boland E, Davidson M (2000) Coping skills training for youth with diabetes mellitus has long lasting effects on metabolic control and quality of life. J Pediatrics 137: 107-113.

17. Barnard KD, Skinner TC, Peveler R (2011) the prevalence of co-morbid depression in adults with Type 1 diabetes: systematic literature review. Diabet Med 23: 445-448. 